\title{
Y-doped AICoCrFeNi2.1 eutectic high-entropy alloy with excellent oxidation resistance and structure stability at $1000^{\circ} \mathrm{C}$ and $1100^{\circ} \mathrm{C}$
}

DOI:

10.1016/j.corsci.2020.109191

\section{Document Version}

Accepted author manuscript

Link to publication record in Manchester Research Explorer

Citation for published version (APA):

Lu, J., Zhang, H., Chen, Y., Li, L., Liu, X., Xiao, W., Ni, N., Zhao, X., Guo, F., \& Xiao, P. (2021). Y-doped AlCoCrFeNi2. 1 eutectic high-entropy alloy with excellent oxidation resistance and structure stability at $1000^{\circ} \mathrm{C}$ and $1100^{\circ}$ C. Corrosion Science, 180, 109191. https://doi.org/10.1016/j.corsci.2020.109191

\section{Published in:}

Corrosion Science

\section{Citing this paper}

Please note that where the full-text provided on Manchester Research Explorer is the Author Accepted Manuscript or Proof version this may differ from the final Published version. If citing, it is advised that you check and use the publisher's definitive version.

\section{General rights}

Copyright and moral rights for the publications made accessible in the Research Explorer are retained by the authors and/or other copyright owners and it is a condition of accessing publications that users recognise and abide by the legal requirements associated with these rights.

\section{Takedown policy}

If you believe that this document breaches copyright please refer to the University of Manchester's Takedown Procedures [http://man.ac.uk/04Y6Bo] or contact uml.scholarlycommunications@manchester.ac.uk providing relevant details, so we can investigate your claim.

\section{OPEN ACCESS}


Y-doped AICoCrFeNi $i_{2.1}$ eutectic high-entropy alloy with excellent oxidation resistance and structure stability at $1000^{\circ} \mathrm{C}$ and $1100{ }^{\circ} \mathrm{C}$

Jie Lu a, Han Zhang a, Ying Chen b, Ling Lia, Xuanzhen Liv a, Weiwei Xiaoc, $\mathrm{Na} \mathrm{Nic,} \mathrm{Xiaofeng} \mathrm{Zhao} \mathrm{a,*,} \mathrm{Fangwei} \mathrm{Guo} \mathrm{a,} \mathrm{Ping} \mathrm{Xiao} \mathrm{a}$

a Shanghai Key Laboratory of Advanced High-Temperature Materials and Precision Forming, School of Materials Science and Engineering, Shanghai Jiao Tong University, Shanghai, 200240, China

b School of Materials, The University of Manchester, Manchester M13 9PL, United Kingdom

c Key Lab of Education Ministry for Power Machinery and Engineering, School of Mechanical Engineering, Shanghai Jiao Tong University, Shanghai 200240, China

\begin{abstract}
In this study, the oxidation behavior of $\mathrm{AlCoCrFeNi}_{2.1}$ eutectic high entropy alloy (EHEA) with/without $Y$ doping at $1000^{\circ} \mathrm{C}$ and $1100^{\circ} \mathrm{C}$ was reported. The doping of minor $\mathrm{Y}$ is crucial to improving the $\mathrm{Al}_{2} \mathrm{O}_{3}$ scale adhesion and achieving its durability at high temperatures. The oxidation rates of Y-doped AlCoCrFeNi 2.1 EHEA at $1000^{\circ} \mathrm{C}$ and $1100^{\circ} \mathrm{C}$ are comparable and even lower compared with conventional $\mathrm{Al}_{2} \mathrm{O}_{3-}$ forming NiCoCrAlY/CoNiCrAlY alloys. The superior oxidation resistance and highly stable eutectic lamellar structure after high-temperature oxidation make Y-doped AlCoCrFeNi ${ }_{2.1}$ EHEA show a tremendous potential in high-temperature application.
\end{abstract}

Keywords: High-entropy alloy; Oxidation; $\mathrm{Al}_{2} \mathrm{O}_{3}$ scale; High-temperature 


\section{Introduction}

High-entropy alloys (HEAs), also termed as multi-principal element alloys contain four or more principal elements in equal or non-equal atomic proportion [1-3], which is first proposed by Yeh et al. [4] and Cantor et al.[5] in 2004. HEAs are newly developed class of alloys, since they are substantially different from the conventional alloys (such as superalloys and stainless steels), which have one or two principal matrix elements.

In the last 15 years, two main types of HEAs have been widely designed and investigated because of their excellent physical properties: one is single-phase face-centered cubic (FCC) HEAs, the other one is singlephase body-centered cubic (BCC) HEAs. Single-phase FCC structured HEAs exhibit high tensile ductility but low yield strength (e.g. CoCrFeMnNi HEA) [6]. Single-phase BCC structured HEAs can have very high yield strength, but at the sacrifice of the ductility (e.g. NbMoTaW refractory HEA) [7]. Thus, it is really difficult to realize the balance between high strength and high ductility in a single-phase HEA. Additionally, the inferior cast-ability and compositional segregation are common for a singlephase HEA and thus further limit their engineering applications [8].

To overcome the above limitations, an $\mathrm{AlCoCrFeNi}_{2.1}$ eutectic high entropy alloy (EHEA) with an acceptable cast-ability was developed by Lu et al. [9] to achieve a good combination of high tensile strength ( $>1$ $\mathrm{GPa}$ ) and high tensile ductility (>10\%) at room temperature. More importantly, it is well known that the eutectic solidification structure have provided a solid foundation for high-temperature alloys for application in the high-temperature components of gas turbine engines due to their superior high-temperature stability, which is simply summarized as following: (1) near-equilibrium eutectic structure can effectively resist structural change at temperatures up to their reaction temperature; (2) low-energy lamellar structure can maintain their high thermodynamic stability and kinetic resistance to thermal degradation $[9,10]$.

Additionally, the AICoCrFeNi ${ }_{2.1}$ EHEA exhibits a fine and regular lamellar structure, consisting of coupled grown FCC $\left(\mathrm{LI}_{2}\right) / \mathrm{BCC}$ (B2) phases [8]. On one hand, the $L 1_{2}$ phase, also termed as $Y$ ' phase, is an indispensable strengthening phase in the Ni-base superalloy and the antioxidant $\gamma-\gamma^{\prime}$ bond coat ( $Y$ is a disordered FCC phase) in thermal barrier coatings (TBCs) to maintain their strength at elevated temperatures (e.g. creep resistance) [11-13]. On the other hand, the Al-rich $\mathrm{B} 2$ phase, also termed as $\beta$ phase, is a primary phase constitution to form a protective $\mathrm{Al}_{2} \mathrm{O}_{3}$ scale for the typical oxidation resistant overlay coatings or bond coats (e.g. NiCoCrAlY, Pt/Hf-modified NiAl) [8, 12, 14-18]. First, the high volume fraction of $\beta$ phase (bout $35 \%$ ) is sufficient to support the formation of 
$\mathrm{Al}_{2} \mathrm{O}_{3}$ scale during prolonged oxidation $[8,19]$. Second, the lamellar eutectic structure leads to an elongated phase shape with a large aspect ratio $[8,9,19]$, which is beneficial to facilitate the earlier establishment of $\mathrm{Al}_{2} \mathrm{O}_{3}$ scale through lowering the critical $\mathrm{Al}$ concentration required to form $\mathrm{Al}_{2} \mathrm{O}_{3}[20,21]$. Therefore, the AlCoCrFeNi 2.1 EHEA shows a great potential as a new type of overlay coating or bond coat in TBCs to protect the high-temperature components from oxidation due to its unique eutectic structure and phase constitutions. Moreover, when it comes to the high-temperature application of this $\mathrm{AlCOCrFeNi}_{2.1}$ EHEA, the oxidation resistance of this alloy should be also evaluated in detail. Regrettably, at present, no publications related to the oxidation behavior of AlCoCrFeNi2.1 EHEA can be found.

In this contribution, the oxidation behavior of $\mathrm{AlCOCrFeNi}{ }_{2.1}$ EHEA with minor reactive element $Y$ doping combined with its structure and phase constitutions are systematically investigated at $1000^{\circ} \mathrm{C}$ and $1100^{\circ} \mathrm{C}$ in this study. The objective of $Y$ doping into this alloy is to improve the oxide scale adhesion to metal substrate. The beneficial effect of $Y$ doping on the oxidation resistance has been well documented in the FeCrAlY alloy and NiCoCrAlY alloy $[15,16,22,23]$. Meanwhile, the AICoCrFeNi $i_{2.1}$ EHEA without $Y$ doping was also fabricated to further understand the oxidation behavior of this alloy. Two different test temperatures are selected to clarify the effect of temperature on the oxidation behavior of this alloy. The microstructure and phase constitutions of original alloy, oxidized alloy and oxide scale are characterized in detail for understanding the oxidation mechanism comprehensively.

\section{Materials and method}

\subsection{AlCoCrFeNi 2.1 alloy preparation}

The ingots with a nominal composition of $\mathrm{AlCoCrFeNi}_{2.1}$ (at\%) with doping of 0.05 at\% reactive element $Y(\geqslant 99.9 \mathrm{wt} \%)$ and without $Y$ doping were prepared by arc-melting a mixture of the constituent elements ( $\geqslant 99.9 \mathrm{wt} \%$ ) under a Ti-gettered high-purity argon atmosphere. The melting was repeated at least five times to achieve a good chemical homogeneity of the alloy. The molten alloy was suction-cast into a $15 \mathrm{~mm}$ (width) $\times 90 \mathrm{~mm}$ (length) $\times 6 \mathrm{~mm}$ (thickness) copper mold.

\subsection{Isothermal oxidation test}

The square plates with dimensions of $10 \mathrm{~mm}$ (length) $\times 10 \mathrm{~mm}$ (width) $\times 3 \mathrm{~mm}$ (thickness) were extracted from the as-cast material 
using a precision cut-off machine (Accutom 5, Struers) coupled with a $\mathrm{SiC}$ abrasive cutting blade. All the samples were ground with $\mathrm{SiC}$ abrasive papers and polished using $0.05 \mu \mathrm{m}$ colloidal alumina following standard metallographic approaches. The samples were thoroughly cleaned ultrasonically with acetone prior to oxidation. The isothermal oxidation tests were performed at $1000^{\circ} \mathrm{C}$ and $1100^{\circ} \mathrm{C}$ in a chamber furnace at atmosphere environment up to $500 \mathrm{~h}$. The oxidized samples were removed from the furnace after a required exposure time, and then air-cooled to room temperature outside the furnace in approximately $20 \mathrm{~min}$.

\subsection{Samples characterization}

The microstructure and phase constitutions of original alloy, oxidized alloy and oxide scale are determined by scanning electron microscopy (SEM, Mira3, Tescan) coupled with energy dispersive X-ray spectroscopy (EDS, Oxford Instruments). The scanning transmission electron microscope (STEM, TALOS F200X, FEl, USA) equipped with an energy dispersive X-ray spectroscopy (EDS, XIS Ultra DLD, Kratos, Japan) system operated at $200 \mathrm{kV}$ was employed to identify the microstructure and chemical composition of each phase in the original alloy. The thin lamellae with dimensions of $10 \mu \mathrm{m}$ (length) $\times 5 \mu \mathrm{m}$ (width) $\times 50 \mathrm{~nm}$ (thickness)for TEM was prepared using a focused ion beam (FIB, GAIA3, Tescan, Czech Republic). The Young's modulus (E) and Vickers hardness $(\mathrm{H})$ of the original alloy and alloy substrate after oxidation at $1000^{\circ} \mathrm{C}$ and $1100^{\circ} \mathrm{C}$ were obtained from the load-displacement curves produced by micro-indentation (Anton Paar, CPX MHT, Austria) with a diamond Vickers indenter.

\section{Results}

\subsection{Microstructure and composition of Y-doped AICoCrFeNi $2_{2.1}$ EHEA}

Fig. 1 shows the microstructure of Y-doped AICoCrFeNi $i_{2.1}$ EHEA. As shown in Fig. 1a, the alloy exhibits a typical eutectic lamellar structure, composed of fine and regular two phases. Previous literature reports suggested that the bright and dark contrasts correspond to a FCCordered $\mathrm{L} 1_{2}$ phase $\left(\mathrm{Y}^{\prime}\right)$ and a BCC-ordered B2 phase ( $\beta$ ), respectively [8, $9,19,24]$. Two characteristic morphologies can be observed in the alloy: one is the region A (Fig. 1b), where the elongated two phases with a large aspect ratio are well aligned in lamellar structure; other one is the region $B$ (Fig. 1C), where the two phases are intertwined in the shape of 
a maze. According to the EDS maps, the $Y^{\prime}$ phase is enriched with Fe, $\mathrm{Co}$ and $\mathrm{Cr}$ and the $\beta$ phase is enriched with $\mathrm{Ni}$ and $\mathrm{Al}$. Minor $\mathrm{Y}$ is doped into this alloy, but no $Y$-rich precipitates can be found, probably due to the low concentration of $Y(0.05$ at\%) and its adequate solution.
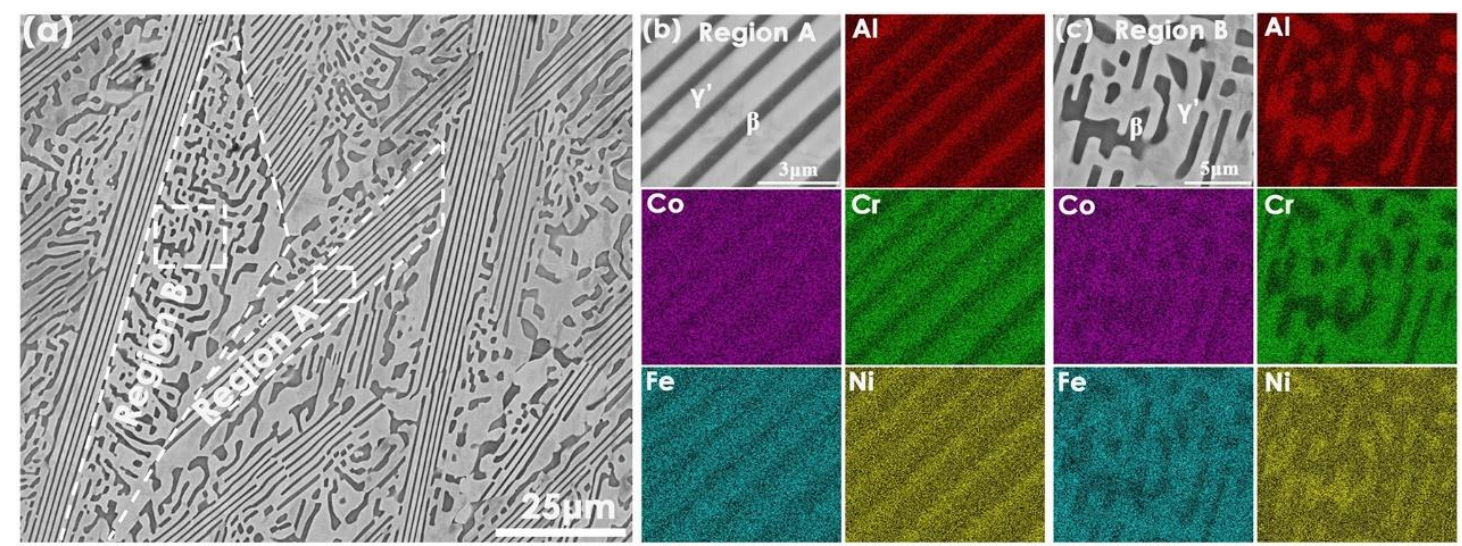

Fig. 1 Microstructure and phase composition of Y-doped AlCoCrFeNi2.1 EHEA: (a) a low magnification back-scattered (BSE) image, showing the overall surface morphology of the alloy; $(b, c)$ amplifying BSE images of the rectangular regions marked in (a) with the corresponding SEM-EDS maps, showing the elemental distribution in each phase.

TEM analysis was employed to accurately identify the structure and chemical composition of each phase in the Y-doped AlCoCrFeNi2.1 EHEA, as presented in Fig. 2. It can be clearly seen in the Fig. 2a collected from the region $A$ that the widths of two phases are both in submicron scale $(<1 \mu \mathrm{m})$. Meanwhile, in some locations in the regions $B$, the sizes of two phases are slightly larger, but less than $5 \mu \mathrm{m}$ (Fig. 1a). Selected area diffraction patterns (SADPs) with superlattice spots (marked in red circles in Fig. $2 b$ and $c$ ) recorded from the two phases clearly indicate that the alloy consists of $Y^{\prime}$ phase with an ordered $\mathrm{L}_{2}$ structure and $\beta$ phase with an ordered B2 structure. The STEM-EDS maps corresponding to the Fig. $2 a$ also manifest that $\gamma^{\prime}$ phase is FeCoCr-rich and $\beta$ phase is NiAl-rich. This result agrees well with that from the SEM-EDS maps (Fig. 1). The chemical composition of $Y^{\prime}$ and $\beta$ phases is also obtained using STEM-EDS point analysis, which is presented Table 1. 


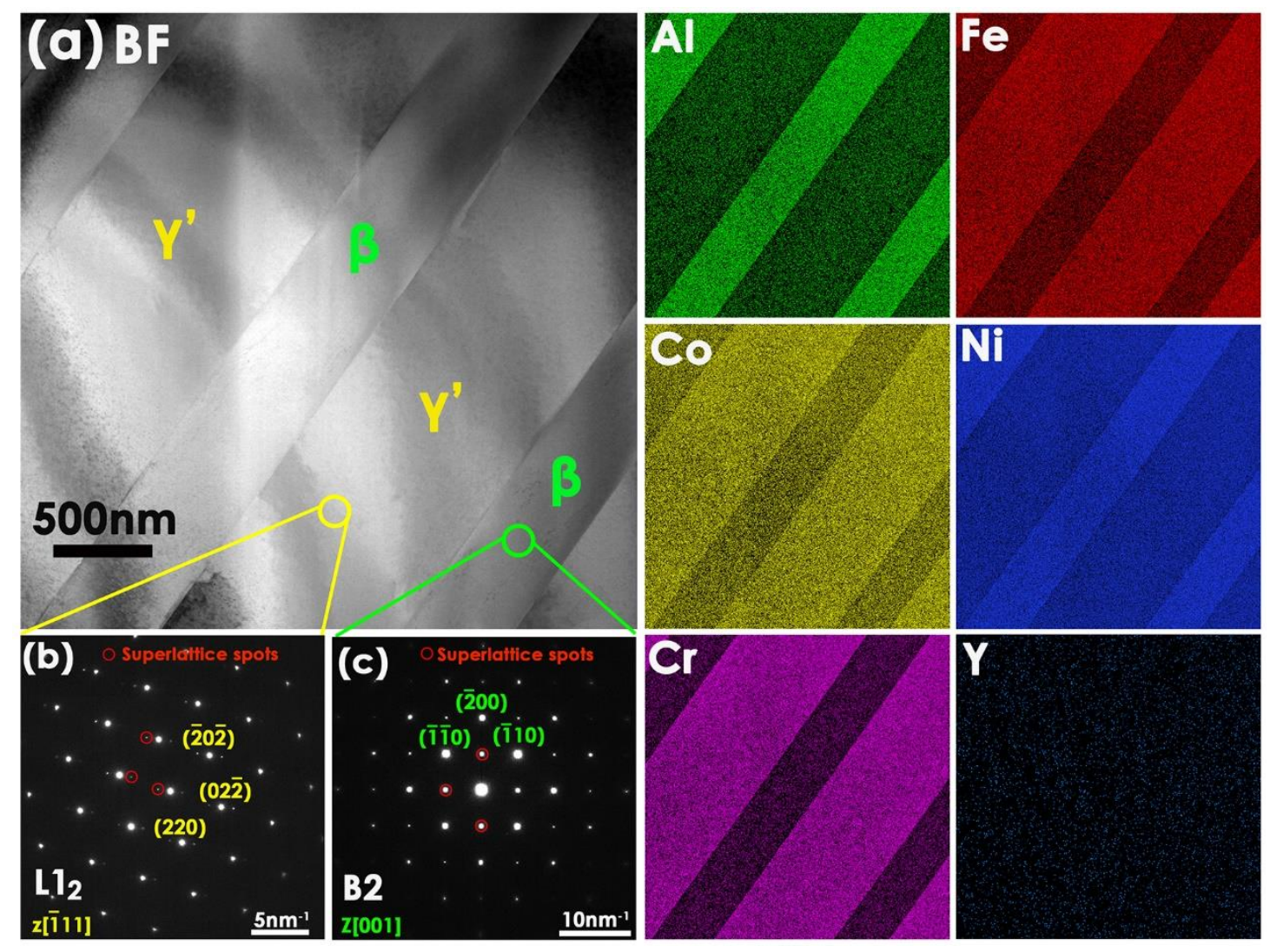

Fig. 2 TEM analysis of Y-doped AICoCrFeNi2.1 EHEA: (a) a bright-field (BF) STEM image and the corresponding STEM-EDS maps, showing the eutectic lamellar morphology of the alloy and phase composition; (b, c) selected area diffraction patterns with superlattice spots, showing the ordered $\mathrm{L}_{2}$ and $\mathrm{B} 2$ structures of two phases.

Table 1. Chemical composition (at\%) of $Y^{\prime}$ and $\beta$ phases in the $Y$-doped AlCoCrFeNi $i_{2.1}$ EHEA.

\begin{tabular}{cccccc}
\hline \multirow{2}{*}{ Phases } & \multicolumn{5}{l}{ Elements (at\%) } \\
\cline { 2 - 6 } & $\mathrm{Al}$ & $\mathrm{Co}$ & $\mathrm{Cr}$ & $\mathrm{Fe}$ & $\mathrm{Ni}$ \\
\hline$Y^{\prime}$ & $9.5 \pm 0.2$ & $19.7 \pm 0.2$ & $19.1 \pm 0.3$ & $19.9 \pm 0.2$ & $31.8 \pm 0.3$ \\
$\beta$ & $29.3 \pm 0.3$ & $12.4 \pm 0.3$ & $4.6 \pm 0.2$ & $9.6 \pm 0.2$ & $44.1 \pm 0.3$ \\
\hline
\end{tabular}

\subsection{Growth of oxide scale}

Fig. 3 shows the surface morphology of oxide scale formed on the $Y$ doped AlCoCrFeNi $i_{2.1}$ EHEA after $96 \mathrm{~h}$ oxidation at $1000^{\circ} \mathrm{C}$ and $1100^{\circ} \mathrm{C}$. After oxidation at $1000^{\circ} \mathrm{C}$ (Fig. 3a), the morphology of oxide scale can be divided into two characteristic regions, which inherit the surface profile of original alloy (Fig. 1). In the region A, the oxide scale is uniform 
$\mathrm{Al}_{2} \mathrm{O}_{3}$ formation (bright contrast) with an extremely small amount of spinel (dark contrast) (Fig. 3b). The spinel contains all base elements in combination with the EDS analysis of point 1, as shown in the inserted image in Fig. $3 \mathrm{~b}$. In this region, the elongated lamellar profile deriving from the original alloy structure can be still seen (Fig. $3 a$ ). In the region $B$ (Fig. 3a), a higher amount of spinel formed at surface and the distribution of spinel corresponds to the surface profile of region $B$ in the original alloy (Fig. 1a). In other words, the oxide constitutions at scale surface at $1000{ }^{\circ} \mathrm{C}$ derives from the initial oxidation stage, which is directly determined by the surface morphology of original alloy. After oxidation at $1100{ }^{\circ} \mathrm{C}$ (Fig. $3 \mathrm{C}$ and $\mathrm{d}$ ), the oxide scale shows a uniform $\mathrm{Al}_{2} \mathrm{O}_{3}$ formation with minor $\mathrm{Cr}$ content (point 2) and no spinel can be seen at scale surface.

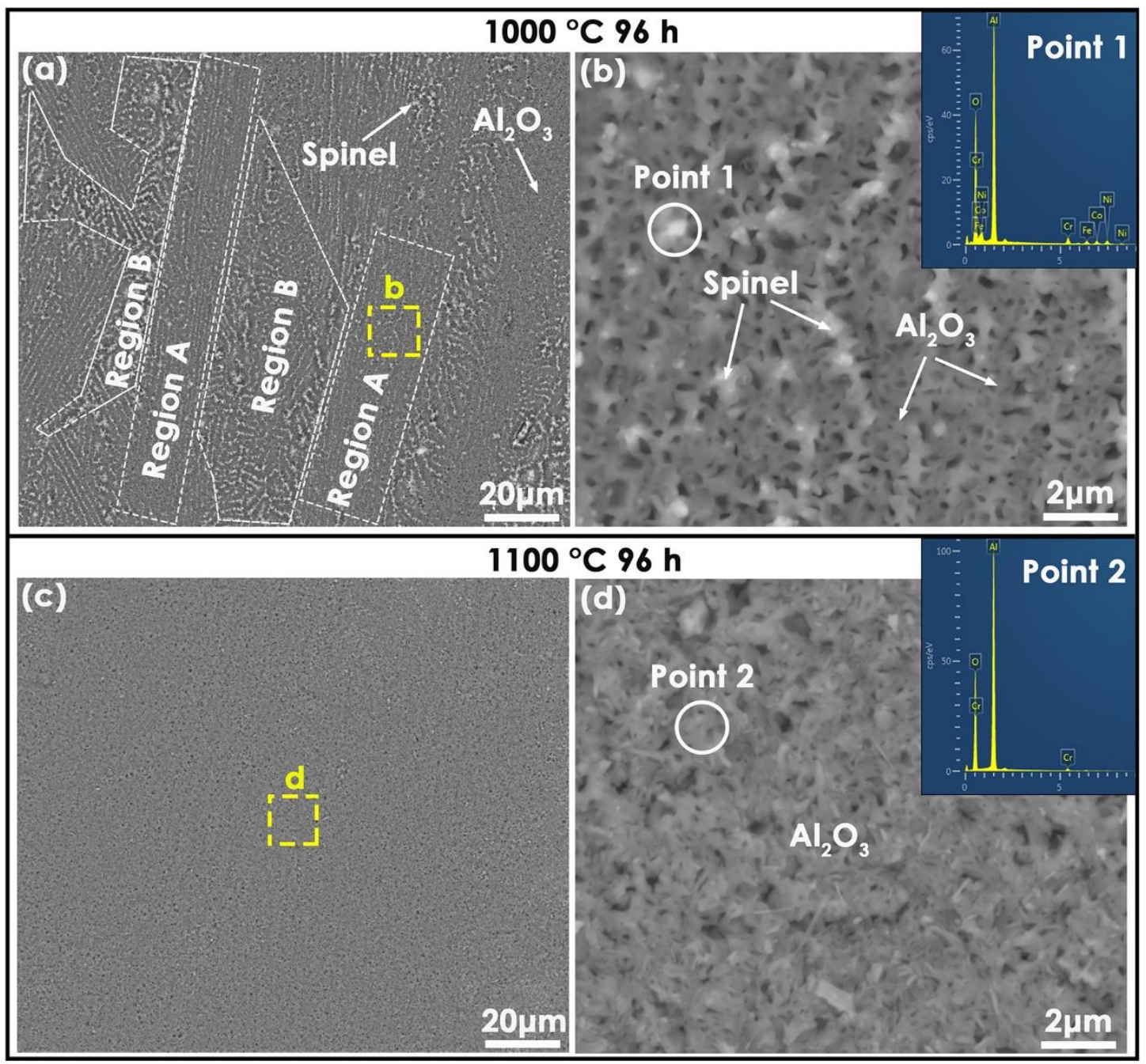

Fig. 3 Surface morphology of oxide scale formed on the Y-doped AlCoCrFeNi $i_{2 .}$ EHEA: (a) a low magnification BSE image, giving an overview of oxide scale after $96 \mathrm{~h}$ oxidation at $1000^{\circ} \mathrm{C}$; (b) amplifying BSE images of the rectangular region marked in (a), showing the detailed grain structure of oxide scale; (c) a low magnification BSE image, giving an overview of oxide scale after $96 \mathrm{~h}$ oxidation at $1100^{\circ} \mathrm{C}$; 
(d) amplifying BSE images of the rectangular region marked in (c), showing the detailed grain structure of oxide scale.

Fig. 4 shows the cross-sectional morphology of oxide scale and alloy substrate after $96 \mathrm{~h}$ oxidation at $1000^{\circ} \mathrm{C}$ and $1100^{\circ} \mathrm{C}$. After oxidation at $1000^{\circ} \mathrm{C}$ (Fig. 4a), it can be clearly seen that a continuous and uniform $\mathrm{Al}_{2} \mathrm{O}_{3}$ scale formed on the alloy in combination with the SEM-EDS maps. The spinel is hardly found from the cross-section of scale, due to its extremely low thickness at scale surface (Fig. 3a). The thickness of $\mathrm{Al}_{2} \mathrm{O}_{3}$ scale reaches about $1.5 \pm 0.3 \mu \mathrm{m}$ after $96 \mathrm{~h}$ oxidation, while a continuous Al-depletion layer with a thickness about $7.2 \pm 2.3 \mu \mathrm{m}$ also develops beneath the $\mathrm{Al}_{2} \mathrm{O}_{3}$ scale, resulting from the growing scale (Fig. 4b). After $96 \mathrm{~h}$ oxidation at $1100^{\circ} \mathrm{C}$ (Fig. $4 \mathrm{C}$ and d), the $\mathrm{Al}_{2} \mathrm{O}_{3}$ scale is much thicker (about $3.4 \pm 0.2 \mu \mathrm{m}$ ), but still continuous and uniform. Meanwhile, the thickness of Al-depletion layer attains about 17.1 $2.2 \mu \mathrm{m}$. For either oxidation test temperature, the scale/alloy interface is smooth and clean and no interfacial imperfections (e.g. pores) occurs, which ensure a good interfacial bonding (Fig. $4 \mathrm{~b}$ and d). Moreover, the typical eutectic lamellar structure of two phases $\left(\gamma^{\prime}+\beta\right)$ is well preserved in the alloy substrate after $96 \mathrm{~h}$ oxidation at $1000^{\circ} \mathrm{C}$ and $1100^{\circ} \mathrm{C}$, suggesting a highly structural stability of this alloy for its high-temperature application.

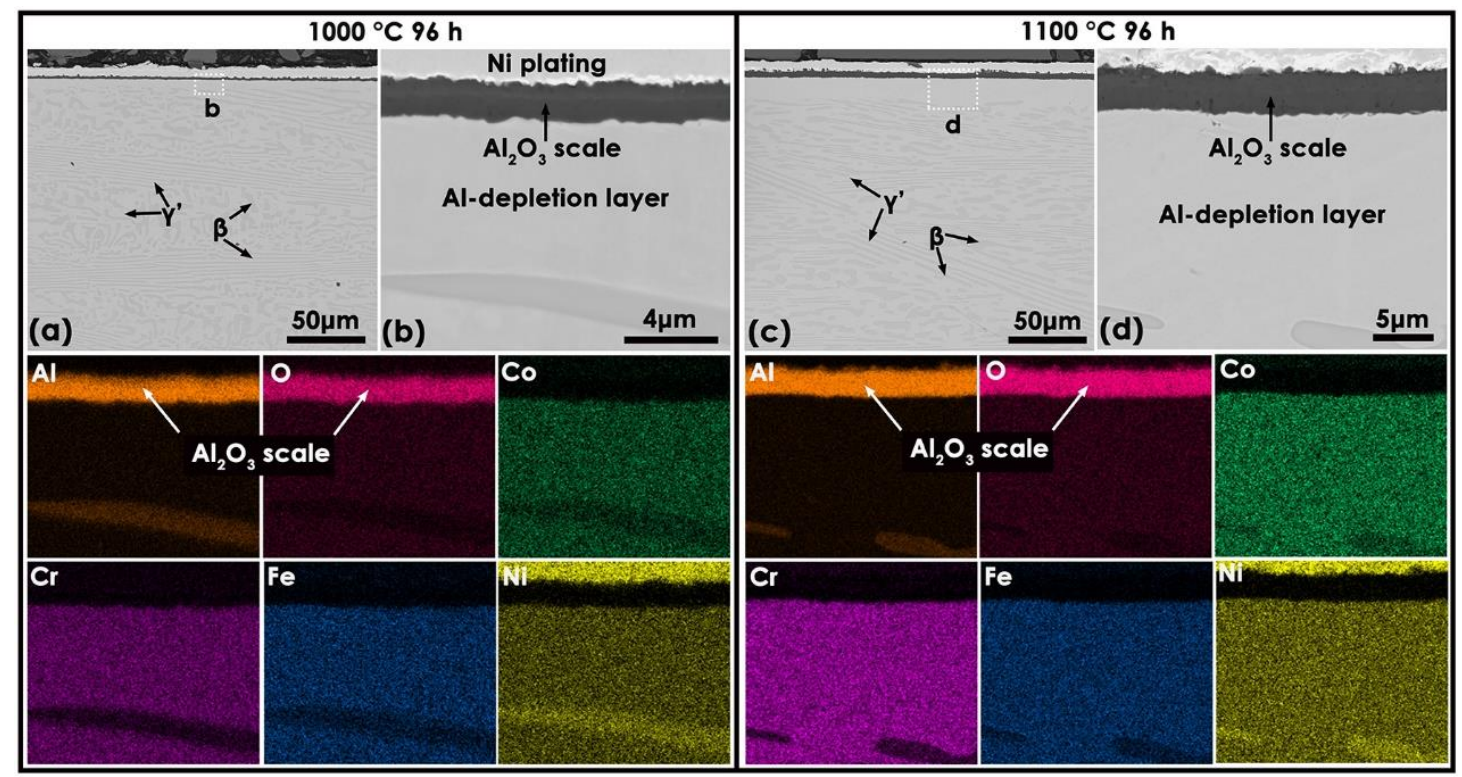

Fig. 4 Cross-sectional microstructure of the Y-doped AICoCrFeNi $i_{2.1}$ EHEA: (a) a low magnification BSE image, giving an overview of oxide scale and alloy substrate after $96 \mathrm{~h}$ oxidation at $1000^{\circ} \mathrm{C}$; (b) amplifying BSE images of the rectangular region marked in (a) and the corresponding SEM-EDS maps, showing the detailed structure and composition of oxide scale and alloy substrate; (c) a low magnification BSE image, giving an overview of oxide scale and alloy substrate after $96 \mathrm{~h}$ oxidation at 
$1100^{\circ} \mathrm{C}$; (d) amplifying BSE images of the rectangular region marked in (c) and the corresponding SEM-EDS maps, showing the detailed structure and composition of oxide scale and alloy substrate.

\subsection{Oxidation kinetics}

According to the results in Fig. 4, the oxide scale predominantly consists of $\mathrm{Al}_{2} \mathrm{O}_{3}$ for the prolonged oxidation process at two test temperatures. In the diffusion-controlled thickening process of $\mathrm{Al}_{2} \mathrm{O}_{3}$, the growth of $\mathrm{Al}_{2} \mathrm{O}_{3}$ scale should follow a parabolic law at either test temperature based on the classical oxidation theory [25]:

$$
h^{2}=k_{h} t \text { (1) }
$$

where $k_{h}, h$ and $t$ are the oxidation rate constant, the thickness of $\mathrm{Al}_{2} \mathrm{O}_{3}$ scale and oxidation time, respectively.

Fig. 5 shows the evolution of $\mathrm{Al}_{2} \mathrm{O}_{3}$ scale thickness for the $\mathrm{Y}$-doped $\mathrm{AlCoCrFeNi}_{2.1}$ EHEA as a function of the square root of oxidation time at $1000^{\circ} \mathrm{C}$ and $1100^{\circ} \mathrm{C}$. Through the linear fitting, the calculated oxidation rate constants at $1000^{\circ} \mathrm{C}$ and $1100^{\circ} \mathrm{C}$ are $6.1 \times 10^{-14} \mathrm{~cm}^{2} / \mathrm{s}$ and $2.9 \times 10^{-}$ $13 \mathrm{~cm}^{2} / \mathrm{s}$, respectively. On the basis of results reported by Evans and Taylor [26], the average oxidation rate constant of a CoNiCrAlY bond coat in TBCs is $9 \times 10^{-13} \mathrm{~cm}^{2} / \mathrm{s}$ at $1100^{\circ} \mathrm{C}$, which is three times higher than that of $\mathrm{Y}$-doped $\mathrm{AlCoCrFeNi}$.1 $\mathrm{EHEA}$ at $1100^{\circ} \mathrm{C}$. 


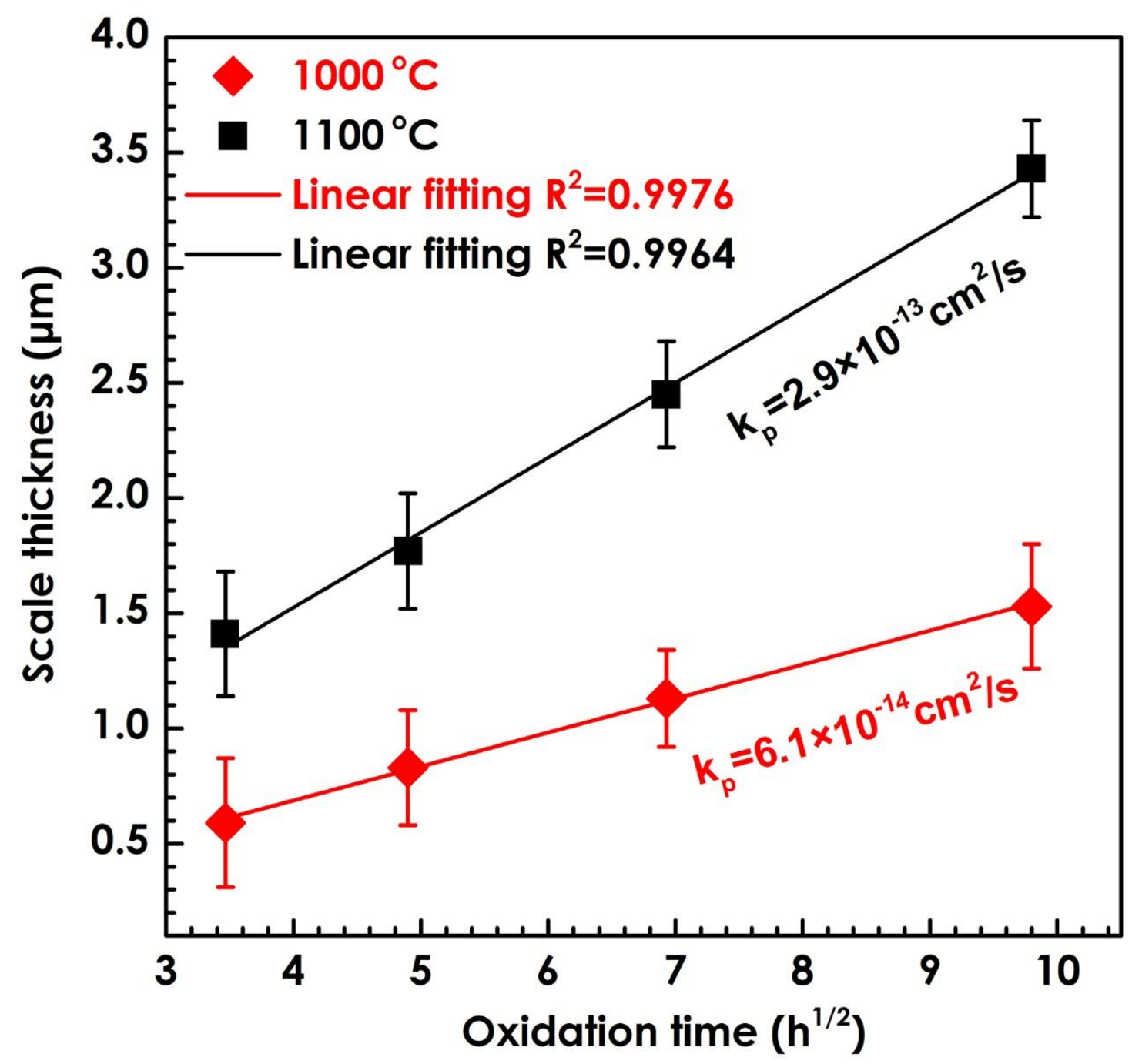

Fig. 5 Evolution of $\mathrm{Al}_{2} \mathrm{O}_{3}$ scale thickness as a function of the square root of oxidation time at $1000^{\circ} \mathrm{C}$.

To better compare oxidation rate with those of commercial $\mathrm{Al}_{2} \mathrm{O}_{3}$ forming NiCoCrAlY/CoNiCrAlY alloys [15, 17, 27, 28], the oxidation rate constants based on the $\mathrm{Al}_{2} \mathrm{O}_{3}$ scale thickness are accurately converted into those based on the mass gain due to the negligible internal oxidation and uniform scale thickness $[26,29]$ :

$$
k_{p}=\left(\frac{3 M_{O} \rho_{\mathrm{Al}_{2} O_{3}}}{M_{A l_{2} O_{3}}}\right)^{2} k_{h}(2)
$$

where $M_{O}(16 \mathrm{~g} / \mathrm{mol})$ and $M_{\mathrm{Al}_{2} \mathrm{O}_{3}}(102 \mathrm{~g} / \mathrm{mol})$ are molar mass of $O$ and $\mathrm{Al}_{2} \mathrm{O}_{3}$, respectively. $\rho_{\mathrm{Al}_{2} \mathrm{O}_{3}}\left(3.98 \mathrm{~g} / \mathrm{cm}^{3}\right)$ is the density of $\mathrm{Al}_{2} \mathrm{O}_{3}$.

Thus, the calculated oxidation rate constants based on the mass gain are $2.1 \times 10^{-13} \mathrm{~g}^{2} \mathrm{~cm}^{-4} \mathrm{~s}^{-1}$ and $1.0 \times 10^{-12} \mathrm{~g}^{2} \mathrm{~cm}^{-4} \mathrm{~s}^{-1}$, respectively, at $1000^{\circ} \mathrm{C}$ and $1100^{\circ} \mathrm{C}$. Mercier et al.[30] reported an oxidation rate of $7.41 \times 10^{-13}$ 
$\mathrm{g}^{2} \mathrm{~cm}^{-4} \mathrm{~s}^{-1}$ at $1000{ }^{\circ} \mathrm{C}$ for a nanostructured CoNiCrAlY coating by high velocity oxygen fuel (HVOF) using milled powder, which is much higher than that Y-doped $\mathrm{AlCoCrFeNi}_{2.1}$ EHEA at $100{ }^{\circ} \mathrm{C}$. Hejrani and his Coworkers [31] fabricated a free-standing NiCoCrAlY coating using highvelocity atmospheric plasma spraying (HV-APS). Its oxidation rate at $1100^{\circ} \mathrm{C}$ is $6 \times 10^{-12} \mathrm{~g}^{2} \mathrm{~cm}^{-4} \mathrm{~s}^{-1}$, which is about six times higher than that of Y-doped AlCoCrFeNi2.1 EHEA at $1100^{\circ} \mathrm{C}$. In our previous work [32], an improved NiCoCrAlY alloy was prepared via powder milling and spark plasma sintering. Its oxidation rate at $1100^{\circ} \mathrm{C}$ is $1.4 \times 10^{-12} \mathrm{~g}^{2} \mathrm{~cm}^{-4} \mathrm{~s}^{-1}$, which is comparable to that of Y-doped AlCoCrFeNi2.1 EHEA at $1100^{\circ} \mathrm{C}$. It is difficult to accurately compare the oxidation rate of $Y$-doped AlCoCrFeNi $i_{2.1}$ alloy with those of NiCoCrAlY/CoNiCrAlY alloys, but it can be proposed that the oxidation rates of Y-doped AlCoCrFeNi $2_{2.1}$ EHEA at $1000^{\circ} \mathrm{C}$ and $1100^{\circ} \mathrm{C}$ are comparable and even lower in comparison to those of $\mathrm{Al}_{2} \mathrm{O}_{3}$-forming NiCoCrAlY/CoNiCrAlY alloys.

\section{Discussion}

\subsection{Necessity of $\mathrm{Y}$ doping to $\mathrm{Al}_{2} \mathrm{O}_{3}$ scale adhesion for the $\mathrm{AlCoCrFeNi}{ }_{2.1}$}

\section{EHEA}

To understand effect of $Y$ on the oxidation performance of $\mathrm{AlCoCrFeNi}{ }_{2.1}$ EHEA, Fig. 6 shows the surface morphology of oxide scale formed on the Y-free AlCoCrFeNi $i_{2.1}$ EHEA after $96 \mathrm{~h}$ oxidation at $1000^{\circ} \mathrm{C}$ and $1100^{\circ} \mathrm{C}$. The oxide constitutions at scale surface for the $\mathrm{Y}$-free alloy are substantially consistent with those at scale surface for the $Y$-doped alloy after $96 \mathrm{~h}$ oxidation at $1000^{\circ} \mathrm{C}$ (Fig. $3 \mathrm{a}$ and $6 \mathrm{a}$ ). However, the oxide scale for the $Y$-free alloy undergoes devastating spallation from the scale/alloy interface, revealing an extremely inferior interfacial adhesion. A further observation on the spalled interface shows that a large amount of interfacial pores occur at interface and thus rapidly degrade the interfacial adhesion (Fig. 6b). It is considered that the formation of these pores at interface originates from vacancy condensation and the source of vacancies is the Kirkendall effect in the alloy as described by Kuenzly and Douglass [33]. For the Y-free AICoCrFeNi 2.1 EHEA, the growth of $\mathrm{Al}_{2} \mathrm{O}_{3}$ scale is controlled by the concurrent diffusion of $\mathrm{Al}$ and $\mathrm{O}$. The outward $\mathrm{Al}$ diffusion to $\mathrm{Al}_{2} \mathrm{O}_{3}$ scale leads to the inward difusion of other metal elements to alloy. The different diffusion rate of Al and other metal elements due to the Kirkendall effect causes the formation of interfacial pores. 


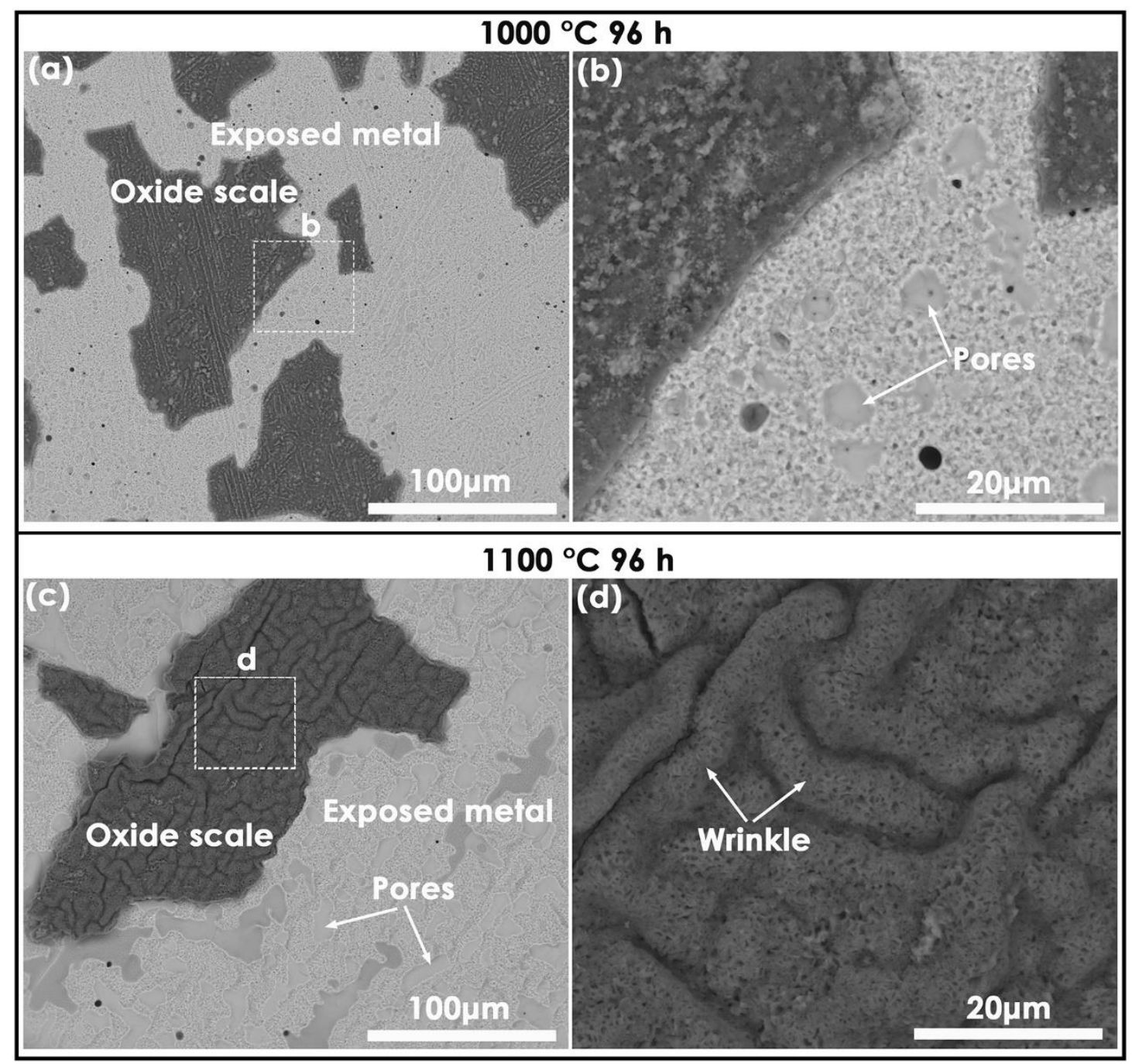

Fig. 6 Surface morphology of oxide scale formed on the Y-free AICoCrFeNi2.1 EHEA: (a) a low magnification BSE image, giving an overview of oxide scale surface after $96 \mathrm{~h}$ oxidation at $1000{ }^{\circ} \mathrm{C}$; (b) amplifying BSE images of the rectangular region marked in (a), showing the exposed metal surface; (c) a low magnification BSE image, giving an overview of oxide scale surface after $96 \mathrm{~h}$ oxidation at $1100{ }^{\circ} \mathrm{C}$; (d) amplifying BSE images of the rectangular region marked in (c), showing the detailed scale structure.

The oxide scale is an exclusive $\mathrm{Al}_{2} \mathrm{O}_{3}$ formation for the $\mathrm{Y}$-free alloy after $96 \mathrm{~h}$ oxidation at $1100^{\circ} \mathrm{C}$ (Fig. 6C), but the $\mathrm{Al}_{2} \mathrm{O}_{3}$ scale develops severe scale wrinkling with a highly convoluted configuration (Fig. 6d). According to the model proposed by Golightly et al. [23], the scale wrinkling results from the lateral growth of oxide for the $\mathrm{Y}$-free $\mathrm{Al}_{2} \mathrm{O}_{3}$ forming alloy (e.g. FeCrAl). However, no scale wrinkling can be observed at scale surface for the Y-doped alloy after $96 \mathrm{~h}$ oxidation at $1000^{\circ} \mathrm{C}$ (Fig. $6 a)$, possibly due to the limited lateral growth of oxide within the external 
oxide layer resulting from the much lower oxidation rate at $1000^{\circ} \mathrm{C}$ than that at $1100^{\circ} \mathrm{C}$ (Fig. 5).

To reveal the oxidation mechanism of $\mathrm{Y}$-free $\mathrm{AlCoCrFeNi}{ }_{2.1}$ EHEA more clearly, the cross-sectional morphology of $\mathrm{Y}$-free AICoCrFeNi ${ }_{2.1}$ EHEA after $96 \mathrm{~h}$ oxidation at $1000^{\circ} \mathrm{C}$ and $1100^{\circ} \mathrm{C}$ is presented in Fig. 7. Two features should be noted for the $\mathrm{Y}$-free alloy after $96 \mathrm{~h}$ oxidation at $1000{ }^{\circ} \mathrm{C}$ (Fig. 7a and b): first, the $\mathrm{Al}_{2} \mathrm{O}_{3}$ scale has already detached from the underlying metal during cooling, even if the scale does not spall from the surface for the moment; second, in combination with SEM-EDS maps, the oxide scale predominantly comprises $\mathrm{Al}_{2} \mathrm{O}_{3}$, which is same oxide constitution as that of the Y-doped alloy. An important point should be mentioned for the Y-free alloy after $96 \mathrm{~h}$ oxidation at $1100^{\circ} \mathrm{C}$ (Fig. $7 \mathrm{C}$ and d): a thin but continuous $\mathrm{Al}_{2} \mathrm{O}_{3}$ scale form at the spalled interface in conjunction with the SEM-EDS maps. This result indicates that the scale wrinkling leads to the interfacial separation at high temperature $\left(1100^{\circ} \mathrm{C}\right)$ and then the alloy was re-oxidized to form a thin and dependent $\mathrm{Al}_{2} \mathrm{O}_{3}$ scale due to the low oxygen partial pressure at interface.

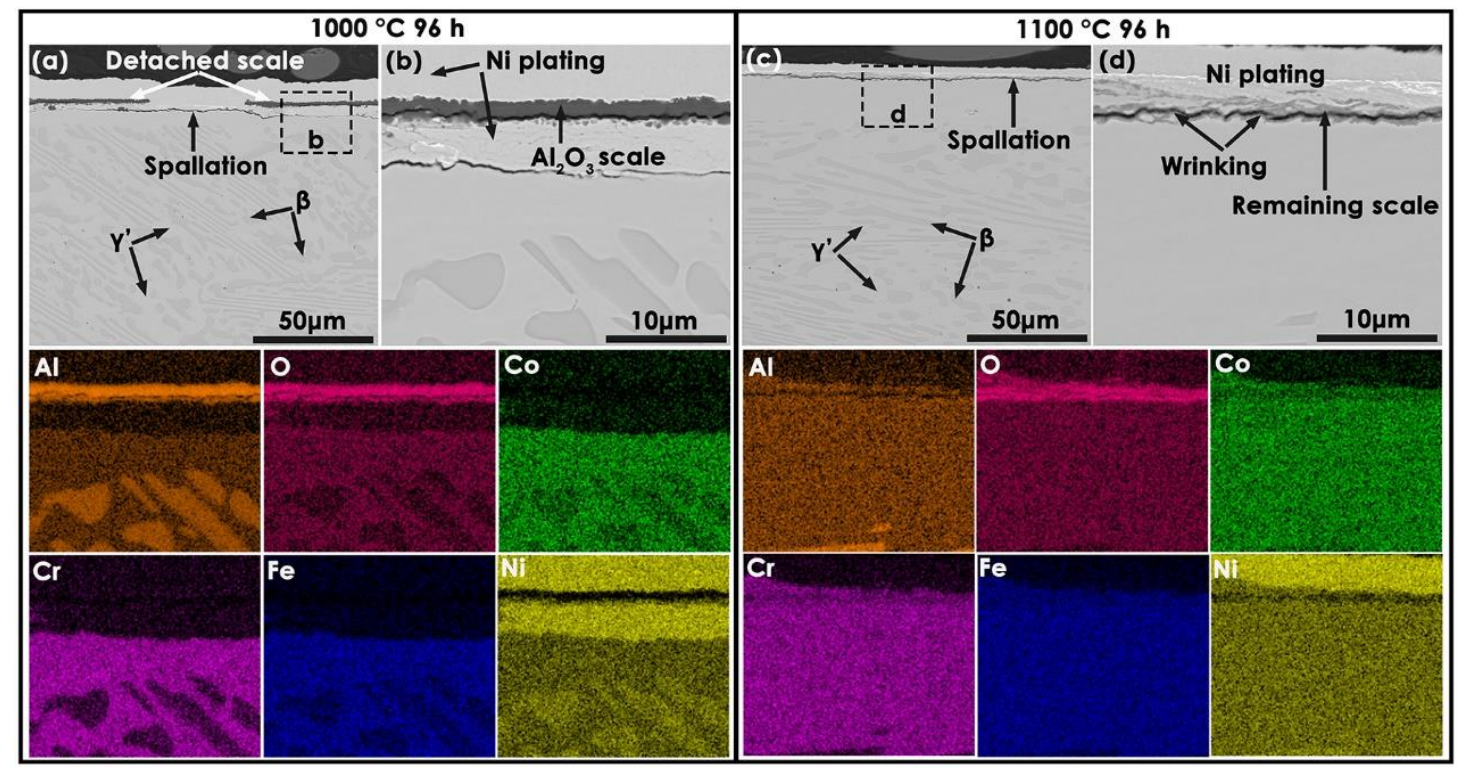

Fig. 7 Cross-sectional microstructure of the Y-free AICoCrFeNi ${ }_{2.1}$ EHEA: (a) a low magnification BSE image, giving an overview of oxide scale and alloy substrate after $96 \mathrm{~h}$ oxidation at $1000^{\circ} \mathrm{C}$; (b) amplifying BSE images of the rectangular region marked in (a) and the corresponding SEM-EDS maps, showing the detailed structure and composition of oxide scale and alloy substrate; (c) a low magnification BSE image, giving an overview of oxide scale and alloy substrate after $96 \mathrm{~h}$ oxidation at $1100^{\circ} \mathrm{C}$; (d) amplifying BSE images of the rectangular region marked in (c) and the corresponding SEM-EDS maps, showing the detailed structure and composition of oxide scale and alloy substrate. 
Thus, doping of $Y$ into the AlCoCrFeNi ${ }_{2.1}$ EHEA is indispensable for improving scale adhesion to achieve its durability at high temperatures. Fig. 8 shows the fractural structure of $\mathrm{Al}_{2} \mathrm{O}_{3}$ scale formed on the $\mathrm{Y}$-doped AlCoCrFeNi $i_{2.1}$ EHEA at $96 \mathrm{~h}$ oxidation at $1000^{\circ} \mathrm{C}$ and $1100^{\circ} \mathrm{C}$. The typical double-layer scale structure composed of the external equiaxed grains and the internal columnar grains in contact with metal substrate (Fig. 8a and $\mathrm{b}$ ). It is extensively accepted for $\mathrm{RE}$-doped $\mathrm{Al}_{2} \mathrm{O}_{3}$-forming alloys that the equiaxed grains forms by the outward Al diffusion and the columnar grains forms by the inward $O$ diffusion [22, 23, 34, 35]. The predominant columnar grain structure of scale indicates that the growth of $\mathrm{Al}_{2} \mathrm{O}_{3}$ scale is dominated by the inward $O$ diffusion [35]. The mechanism of inward $O$ diffusion prevents the formation of oxide within the existing scale, thus inhibiting the scale wrinkling and improving the scale adhesion (Fig. 3 and 4) [23]. In addition, the segregation of $Y$ to scale/metal interface can inhibits interfacial pore growth, presumably due to the presence of adequately efficient vacancy sinks [23, 35]. Based on the discussion mentioned above, doping of $Y$ into the AlCoCrFeNi $i_{2.1}$ EHEA can significantly improve its interfacial adhesion and thus delay its scale failure through suppressing the formation of interfacial pores and scale wrinkling.
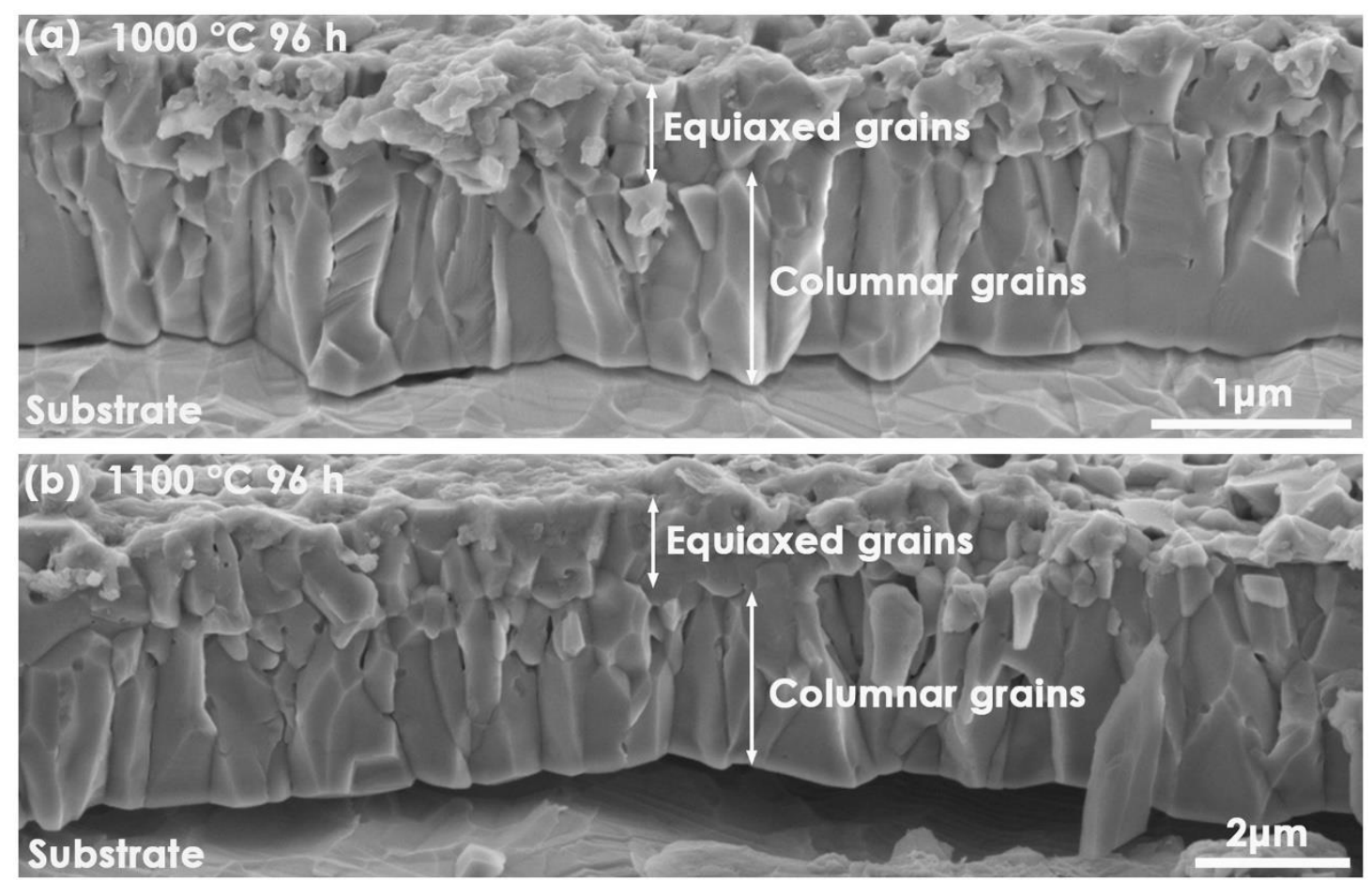

Fig. 8 Fractural structure of $\mathrm{Al}_{2} \mathrm{O}_{3}$ scale formed on the $\mathrm{Y}$-doped AlCoCrFeNi2.1 EHEA at $96 \mathrm{~h}$ oxidation: (a) at $1000^{\circ} \mathrm{C}$; (b) at $1100^{\circ} \mathrm{C}$. 


\subsection{Effect of $\beta$-phase size and shape on oxide constitutions at scale surface for the Y-doped AICoCrFeNi $i_{2.1}$ EHEA}

According to the results presented in Fig. 1 and 3, a higher amount of spinel forms on the region $\mathrm{B}$ at $1000{ }^{\circ} \mathrm{C}$ for the $\mathrm{Y}$-doped $\mathrm{AlCoCrFeNi}{ }_{2.1}$ EHEA, while the scale formed on the region A predominantly consists of an exclusive $\mathrm{Al}_{2} \mathrm{O}_{3}$ plus minor spinel. Based on the model proposed by Wang et al. [29], the exclusive $\mathrm{Al}_{2} \mathrm{O}_{3}$ formation formed on an $\mathrm{Al}_{2} \mathrm{O}_{3}$ forming two-phase alloy is affected by size and shape of the second phase. A finer second phase in the alloy matrix can facilitate the formation of exclusive $\mathrm{Al}_{2} \mathrm{O}_{3}$ under a given second-phase volume fraction. For the Y-doped AlCoCrFeNi ${ }_{2.1}$ EHEA, the second phase is Alrich $\beta$ phase (Table. 1), which uniformly precipitates from the $Y^{\prime}$ matrix (Fig.1). Indeed, the size of $\beta$ phase in region $A$ is slightly smaller than that in region $B$, but it is speculated that the difference in $\beta$-phase size in region $A$ and region $B$ is not primary reason for difference in oxide constitutions, since the $\beta$-phase size is still in one order of magnitude in these two regions.

Therefore, the difference in oxide constitutions in region $A$ and region $B$ is attributed to the substantial difference in $\beta$-phase shape in these two regions. The shape of the second phase has a vital effect on the criterion required for the exclusive oxide formation. The effectiveness (Eff.) of differently shaped second-phase to form exclusive oxide has been well defined by Wang et al. [29]:

$$
\text { Eff. }=\left\{\begin{array}{cc}
3.22 & \begin{array}{c}
\text { sphere } \\
\text { cube }
\end{array} \\
4.0 & \text { cylinder }
\end{array}\right.
$$

where $r$ and I represent radius and length of a cylindrical phase. For a cylindrical phase, the effectiveness is also dependent on the ratio of the length to the radius, which is plotted in Fig. 9. As shown in Fig. 9, a cubic second phase is more effective than a spherical second phase, but a cylindrical second phase is superior to both of them. For the Y-doped AlCoCrFeNi $i_{2.1}$ EHEA, the $\beta$ phase can be thought to be cylindrical shape with a large aspect ratio of the length to the radius (about $20<1 / r<600$ ) in the region $A$, while the cylindrical $\beta$ phase in the region $B$ shows $a$ much lower aspect ratio (about $1<1 / r<20$ ) (Fig. 1a). The measurement of aspect ratio might not be very accurate, but this measurement is close to the actual value. It can be clearly seen in Fig. 9 that the effectiveness to form an exclusive $\mathrm{Al}_{2} \mathrm{O}_{3}$ is much higher in the region $\mathrm{A}$ than that in the region $B$ due to the large aspect ratio of Al-rich $\beta$ phase. 
In addition, some $\beta$ phases closed to cubic or spherical shape can be also observed in the in the region $B$ (Fig. 1 a), which will leads to a further decrease in the effectiveness to form an exclusive $\mathrm{Al}_{2} \mathrm{O}_{3}$ (Fig. 9). Therefore, compared with the region $A$, a higher amount of spinel develops in the region $B$ resulting from the low aspect ratio of spherical $\beta$ phase and the formation of some cubic and spherical $\beta$ phases. The relatively high amount of spinel formed in the region $B$ derives from the initial oxidation stage. After the prolonged oxidation (96 h), the spinel is hardly seen from the cross-section of scale due to its extremely low thickness with respect to the overall scale (Fig. 4a and b). In other words, the thickening of scale during the prolonged oxidation at $1000{ }^{\circ} \mathrm{C}$ is still dominated by the $\mathrm{Al}_{2} \mathrm{O}_{3}$ growth. In addition, the spinel at scale surface is very dispersive and does not form a continuous layer, thus the effect of spinel on the overall scale growth is more negligible(Fig. 3a and b).

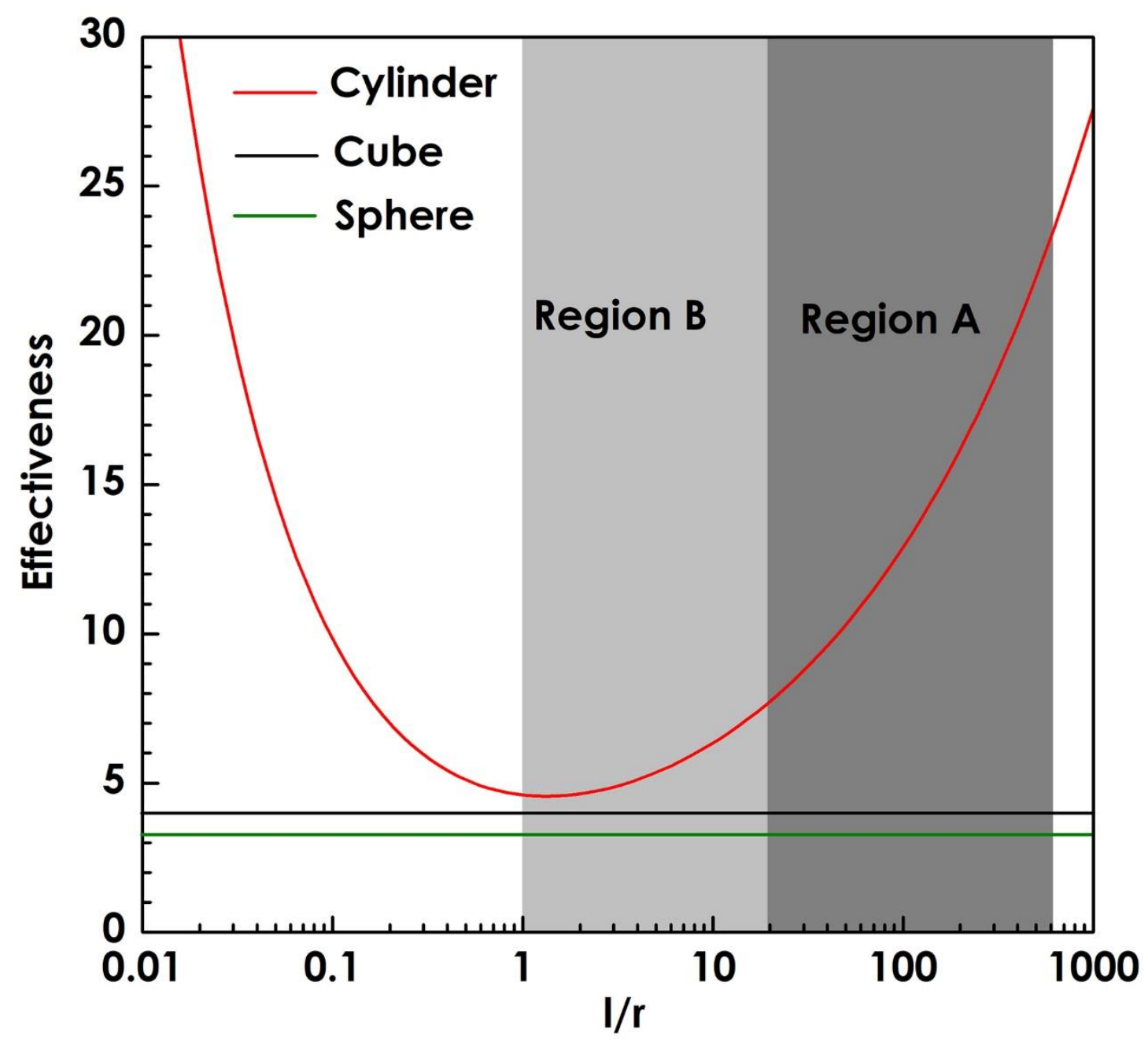

Fig. 9 The dependence of the effectiveness of a cylindrical phase to form an exclusive $\mathrm{Al}_{2} \mathrm{O}_{3}$ on its $\mathrm{r} / \mathrm{l}$ ratio. The effectiveness of spherical and cubic phase is also added in this figure for comparison. 
When the Y-doped AICoCrFeNi $i_{2.1}$ EHEA was oxidized after $96 \mathrm{~h}$ at $1100^{\circ} \mathrm{C}$, the scale surface shows an exclusive $\mathrm{Al}_{2} \mathrm{O}_{3}$ formation without the presence of spinel (Fig. $3 \mathrm{c}$ and d). A higher oxidation temperature at $1100^{\circ} \mathrm{C}$ can enhance the Al activity and thus accelerating the Al flux reaching alloy surface to form $\mathrm{Al}_{2} \mathrm{O}_{3}$. In other words, the temperature is predominant factor rather than $\beta$-phase shape affecting oxide constitutions at scale surface at $1100^{\circ} \mathrm{C}$.

\subsection{Excellent oxidation resistance and structure stability of the Y-doped}

\section{AICoCrFeNi 2.1 EHEA at $1000^{\circ} \mathrm{C}$ and $1100^{\circ} \mathrm{C}$}

To further evaluate the oxidation resistance of $\mathrm{Y}$-doped $\mathrm{AlCoCrFeNi}{ }_{2.1}$ EHEA after prolonged oxidation at $1000^{\circ} \mathrm{C}$ and $1100^{\circ} \mathrm{C}$, Fig. 10 shows the growth of oxide scale and structural evolution of alloy substrate after $500 \mathrm{~h}$ oxidation at $1000^{\circ} \mathrm{C}$ and $1100^{\circ} \mathrm{C}$. First, after $500 \mathrm{~h}$ oxidation at $1000^{\circ} \mathrm{C}$, a higher amount of spinel can be observed in region $\mathrm{B}$, while the oxide scale is predominant $\mathrm{Al}_{2} \mathrm{O}_{3}$ formation in region $\mathrm{A}$ (Fig. 10a and b). However, the oxide scale consists of uniform $\mathrm{Al}_{2} \mathrm{O}_{3}$ after $500 \mathrm{~h}$ oxidation at $1100^{\circ} \mathrm{C}$ (Fig. $10 \mathrm{~g}$ and h). These results are highly consistent with those after $96 \mathrm{~h}$ oxidation at $1000^{\circ} \mathrm{C}$ and $1100^{\circ} \mathrm{C}$ (Fig. 3). More importantly, the $\mathrm{Y}$-doped AICoCrFeNi ${ }_{2.1}$ EHEA exhibits a strong resistance to scale spallation, since no spallation of oxide scale occurs, even if the alloy is oxidized for $500 \mathrm{~h}$ at $1000^{\circ} \mathrm{C}$ and $1100^{\circ} \mathrm{C}$.

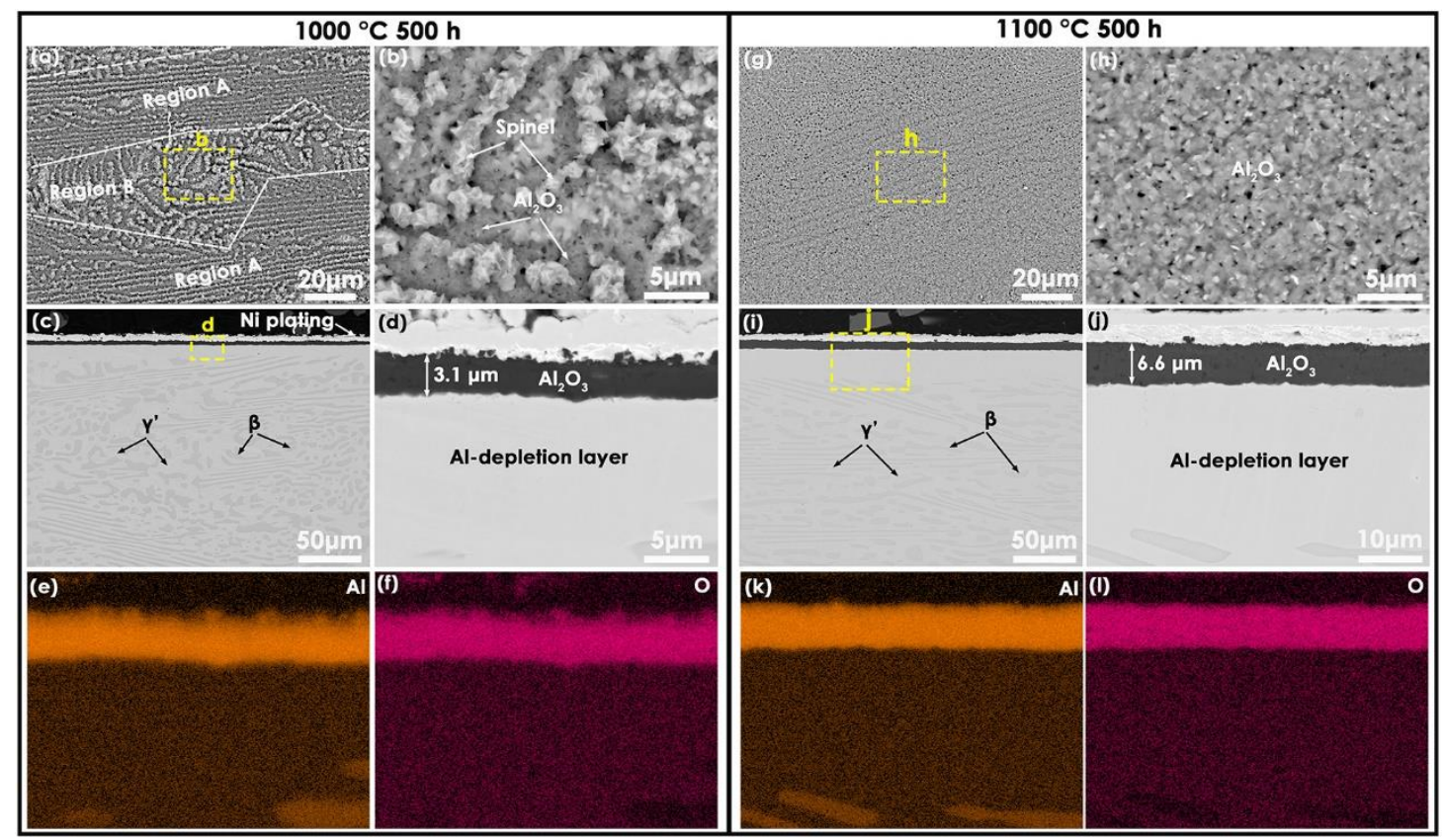

Fig. 10 Surface and cross-sectional microstructure of the Y-doped AlCoCrFeNi $i_{2.1}$ EHEA: $(a, b)$ surface morphology of oxide scale after 500 $\mathrm{h}$ oxidation at $1000{ }^{\circ} \mathrm{C}$; (c-f) cross-sectional morphology and 
composition of oxide scale and alloy substrate after $500 \mathrm{~h}$ oxidation at $1000^{\circ} \mathrm{C} ;(\mathrm{g}, \mathrm{h})$ surface morphology of oxide scale after $500 \mathrm{~h}$ oxidation at $1100{ }^{\circ} \mathrm{C}$; (i-I) cross-sectional morphology and composition of oxide scale and alloy substrate after $500 \mathrm{~h}$ oxidation at $1100^{\circ} \mathrm{C}$.

It can be clearly seen that the $\mathrm{Al}_{2} \mathrm{O}_{3}$ scale thickens uniformly and slowly, and reaches about $3.1 \pm 0.3 \mu \mathrm{m}\left(1000^{\circ} \mathrm{C}\right)$ and $6.6 \pm 0.2 \mu \mathrm{m}\left(1100^{\circ} \mathrm{C}\right)$ respectively after $500 \mathrm{~h}$ oxidation (Fig $10 \mathrm{c}-\mathrm{f}$ and $\mathrm{i}-\mathrm{I}$ ). It should be specially noted that the $\mathrm{Al}_{2} \mathrm{O}_{3}$ scale is well adherent to the alloy substrate and no interfacial imperfections can be found (e.g. cracks or pores) after $500 \mathrm{~h}$ oxidation, thus contributing to a good interfacial bonding during prolonged oxidation (Fig. 10d and j). Additionally, the alloy substrate is still eutectic lamellar structure of $Y^{\prime}$ and $\beta$ phases and no other phases precipitate from the alloy substrate after $500 \mathrm{~h}$ oxidation (Fig. 10c and i). Highly stable eutectic lamellar structure is also beneficial to the scale/metal interface stability, thus improving scale adhesion.

The structural stability of Y-doped AICoCrFeNi2.1 EHEA after oxidation is of very importance to its practical application at high temperatures. In theory, the stability of mechanical properties at room temperature for this alloy after oxidation can reflect the structural stability of this alloy to some extent. Fig. 11 shows the positions and results of micro-indentation test from the original alloy, alloy after $96 \mathrm{~h}$ oxidation at $1000^{\circ} \mathrm{C}$ and alloy after $96 \mathrm{~h}$ oxidation at $1100^{\circ} \mathrm{C}$. The Young's modulus $(\mathrm{E})$ and Vickers hardness $(\mathrm{H})$ of alloy after $96 \mathrm{~h}$ oxidation at $1000^{\circ} \mathrm{C}$ are $155 \pm 7 \mathrm{GPa}$ and $3189 \pm 73 \mathrm{MPa}$, respectively, which are almost same as those $(E=153 \pm 6$ $\mathrm{GPa}, \mathrm{H}=3195 \pm 68 \mathrm{MPa}$ ) of original alloy (Fig. $11 \mathrm{~d}$ and e). Interestingly, the $\mathrm{E}(183 \pm 6 \mathrm{GPa})$ and $\mathrm{H}(4187 \pm 89 \mathrm{MPa})$ of alloy are significantly increased after oxidation at $1100^{\circ} \mathrm{C}$ (Fig. 11 f), but the reasons for such tremendous improvement in mechanical properties is still unclear, which requires a further work. In addition, the focused distribution of five loaddisplacement curves (Fig. $11 \mathrm{~d}$, e and f) and low error bars of $\mathrm{E}$ and $\mathrm{H}$ also reveal a highly structural homogeneity of original alloy and oxidized alloy. The superior structural stability can be attributed to the low-energy lamellar structure, which is intrinsically thermodynamically stable and kinetic resistance to thermal degradation $[9,10]$. To prove its superior structural stability directly, the phase constitutions and mechanical properties of AlCoCrFeNi ${ }_{2.1}$ EHEA at high temperatures are deserved to be investigated in later work. 


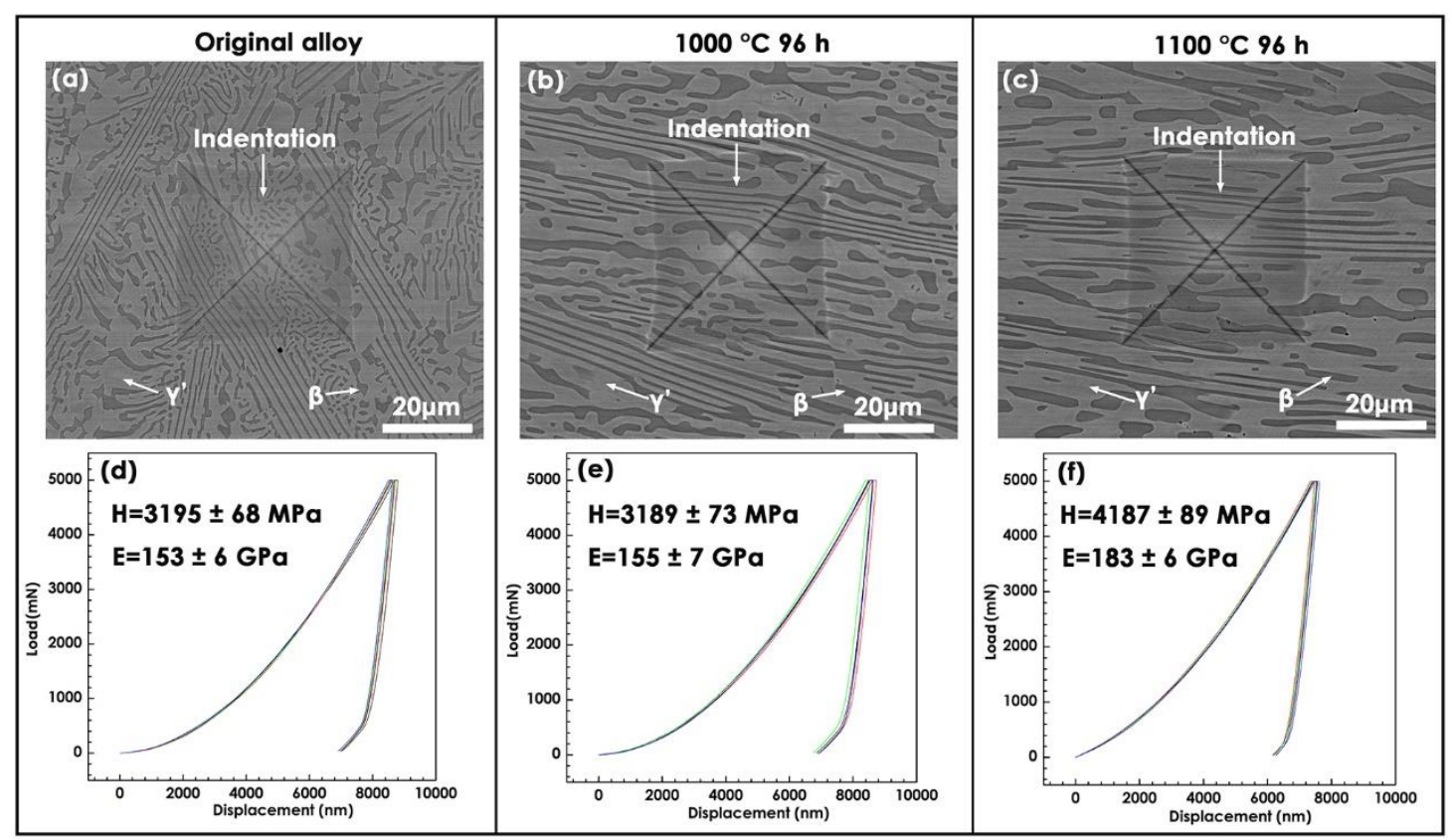

Fig. 11 Micro-indentation test of Y-doped AICoCrFeNi2.1 EHEA: (a, b and c) low magnification BSE images, showing the positions of indentation on the original alloy, alloy after $96 \mathrm{~h}$ oxidation at $1000^{\circ} \mathrm{C}$ and alloy after 96 h oxidation at $1100^{\circ} \mathrm{C}$, respectively; (d, e and f) the Young's modulus (E) and Vickers hardness $(\mathrm{H})$ of the original alloy, alloy after $96 \mathrm{~h}$ oxidation at $1000{ }^{\circ} \mathrm{C}$ and alloy after $96 \mathrm{~h}$ oxidation at $1100{ }^{\circ} \mathrm{C}$ from the loaddisplacement curves. The values of $\mathrm{E}$ and $\mathrm{H}$ are obtained by the average values from five different positions and the error bars are the standard deviations.

In short, the excellent oxidation and spallation resistance, and highly stable eutectic lamellar structure composed of $Y^{\prime}$ and $\beta$ phases of the $Y$ doped AlCoCrFeNi2.1 EHEA guarantee its possibility of high-temperature application.

\section{Conclusions}

In this study, the oxidation behavior of AlCoCrFeNi2.1 EHEA with/without $Y$ doping at $1000^{\circ} \mathrm{C}$ and $1100^{\circ} \mathrm{C}$ was systematically investigated. The following conclusions can be drawn:

(1) The as-cast AlCoCrFeNi ${ }_{2.1}$ EHEA exhibits a typical eutectic lamellar structure composed of a FCC-ordered $L 1_{2}$ phase ( $Y^{\prime}$ ) and a BCCordered B2 phase ( $\beta$ ). The $Y^{\prime}$ phase is enriched with $\mathrm{Fe}, \mathrm{Co}$ and $\mathrm{Cr}$ and the $\beta$ phase is enriched with $\mathrm{Ni}$ and $\mathrm{Al}$.

(2) For the Y-free AICoCrFeNi 2.1 EHEA, a large amount of interfacial pores develop at the scale/metal interface after oxidation at $1000^{\circ} \mathrm{C}$ and $1100^{\circ} \mathrm{C}$, while the severe scale wrinkling forms due to the substantial 
lateral growth of oxide within the existing oxide layer after oxidation at $1100^{\circ} \mathrm{C}$. The formation of interfacial pores and scale wrinkling lead to a rapid degradation of scale adhesion and thus accelerates the scale failure.

(3) For the Y-doped AlCoCrFeNiz.1 EHEA, the formation of interfacial pores and scale wrinkling can be completely suppressed on the account of the minor reactive element $Y$ doping. Thus, the $Y$-doped AlCoCrFeNi ${ }_{2.1}$ EHEA shows a superior scale adhesion to the Y-free AlCoCrFeNi ${ }_{2.1}$ EHEA after high-temperature oxidation. In other words, doping of $\mathrm{Y}$ into the AlCoCrFeNi2.1 EHEA is of great importance to improving scale adhesion for achieving its durability at high temperatures.

(4) The Al-rich $\beta$ phase with a high aspect ratio is beneficial to facilitate the exclusive formation of $\mathrm{Al}_{2} \mathrm{O}_{3}$ scale after oxidation at $1000^{\circ} \mathrm{C}$, while the $\beta$ phase with a low aspect ratio and some cubic or spherical $\beta$ phases tend to cause a higher amount of spinel formation at scale surface. However, at a higher oxidation temperature $\left(1100^{\circ} \mathrm{C}\right)$, the temperature is decisive factor rather than $\beta$-phase shape for the exclusive formation of $\mathrm{Al}_{2} \mathrm{O}_{3}$ scale. In spite of either oxidation temperature $\left(1000{ }^{\circ} \mathrm{C}\right.$ or $\left.1100{ }^{\circ} \mathrm{C}\right)$, the overall thickening of oxide scale is dominated by the growth of $\mathrm{Al}_{2} \mathrm{O}_{3}$ during the prolonged oxidation.

(5) The low oxidation rates $\left(6.1 \times 10^{-14} \mathrm{~cm}^{2} / \mathrm{s}\right.$ at $1000^{\circ} \mathrm{C}$ and $2.9 \times 10^{-13}$ $\mathrm{cm}^{2} / \mathrm{s}$ at $1100^{\circ} \mathrm{C}$ ) and highly stable eutectic lamellar structure consisting of $Y^{\prime}$ and $\beta$ phases for the $Y$-doped AlCoCrFeNi2.1 EHEA after high-temperature oxidation make it show a tremendous potential as an oxidation resistant overlay coating material, bond coat material in TBCs or a high-temperature structural material.

\section{Data availability}

The raw/processed data required to reproduce these findings can be shared upon reasonable requests.

\section{Acknowledgement}

This work was financially supported by National Natural Science Foundation of China (51971139) and National Major Science and Technology Project of China (2017-VI-001 1-0083) 


\section{References}

[1] D.B. Miracle, O.N. Senkov, A critical review of high entropy alloys and related concepts, Acta Mater. 122 (2017) 448-511.

[2] Y. Zhang, T.T. Zuo, Z. Tang, M.C. Gao, K.A. Dahmen, P.K. Liaw, Z.P. Lu, Microstructures and properties of high-entropy alloys, Prog. Mater. Sci. 61 (2014) 1-93.

[3] Y.F. Ye, Q. Wang, J. Lu, C.T. Liu, Y. Yang, High-entropy alloy: challenges and prospects, Mater. Today 19 (2016) 349-362.

[4] J.W. Yeh, S.K. Chen, S.J. Lin, J.Y. Gan, T.S. Chin, T.T. Shun, C.H. Tsau, S.Y. Chang, Nanostructured High-Entropy Alloys with Multiple Principal Elements: Novel Alloy Design Concepts and Outcomes, Adv. Eng. Mater. 6 (2004) 299-303.

[5] B. Cantor, I.T.H. Chang, P. Knight, A.J.B. Vincent, Microstructural development in equiatomic multicomponent alloys, Mater. Sci. Eng. A. 375-377 (2004) 213-218.

[6] B. Gludovatz, A. Hohenwarter, D. Catoor, E.H. Chang, E.P. George, R.O. Ritchie, A fracture-resistant high-entropy alloy for cryogenic applications, Science, 345 (2014) 1153-1158.

[7] Y. Zou, S. Maiti, W. Steurer, R. Spolenak, Size-dependent plasticity in an Nb25Mo25Ta25W25 refractory high-entropy alloy, Acta Mater. 65 (2014) 85-97.

[8] X. Gao, Y. Lu, B. Zhang, N. Liang, G. Wu, G. Sha, J. Liu, Y. Zhao, Microstructural origins of high strength and high ductility in an AlCoCrFeNi2.1 eutectic high-entropy alloy, Acta Mater. 141 (2017) 59-66. [9] Y. Lu, Y. Dong, S. Guo, L. Jiang, H. Kang, T. Wang, B. Wen, Z. Wang, J. Jie, Z. Cao, H. Ruan, T. Li, A promising new class of high-temperature alloys: eutectic high-entropy alloys, Sci Rep, 4 (2014) 6200.

[10] M.E. Glicksman, Principles of Solidification: An Introduction to Modern Casting and Crystal Growth Concepts, Springer, New York, NY, 2011.

[11] R.C. Reed, The superalloys: fundamentals and applications, Cambridge university press, 2008.

[12] J.A. Haynes, B.A. Pint, Y. Zhang, I.G. Wright, Comparison of the oxidation behavior of $\beta$ and $Y-\gamma^{\prime}$ NiPtAl coatings, Surf. Coat. Technol. 204 (2009) 816-819.

[13] H. Yao, L. Yang, Z. Bao, S. Zhu, F. Wang, Low inter-diffusivity Y'-base bondcoats for single crystal superalloy René N5. I: Primary study of microstructures and oxidation behaviors at $1100^{\circ} \mathrm{C}$, Corros. Sci. 147 (2019) 299-312.

[14] J.A. Haynes, B.A. Pint, Y. Zhang, I.G. Wright, Comparison of the cyclic oxidation behavior of $\beta-\mathrm{NiAl}, \beta-\mathrm{NiPtAl}$ and $\gamma-\gamma^{\prime} \mathrm{NiPtAl}$ coatings on various superalloys, Surf. Coat. Technol. 202 (2007) 730-734. 
[15] J.T. DeMasi-Marcin, D.K. Gupta, Protective coatings in the gas turbine engine, Surf. Coat. Technol. 68-69 (1994) 1-9.

[16] G.W. Goward, Progress in coatings for gas turbine airfoils, Surf. Coat. Technol. 108-109 (1998) 73-79.

[17] M.J. Pomeroy, Coatings for gas turbine materials and long term stability issues, Mater. Des. 26 (2005) 223-231.

[18] R.W. Jackson, D.M. Lipkin, T.M. Pollock, Thermal barrier coating adherence to Hf-modified B2 NiAl bond coatings, Acta Mater. 80 (2014) 39-47.

[19] I.S. Wani, T. Bhattacharjee, S. Sheikh, P.P. Bhattacharjee, S. Guo, N. Tsuji, Tailoring nanostructures and mechanical properties of AlCoCrFeNi $i_{2.1}$ eutectic high entropy alloy using thermo-mechanical processing, Mater. Sci. Eng. A., 675 (2016) 99-109.

[20] Y. Chen, X. Zhao, P. Xiao, Effect of microstructure on early oxidation of MCrAlY coatings, Acta Mater. 159 (2018) 150-162.

[21] L. Luo, H. Zhang, Y. Chen, C. Zhao, S. Alavi, F. Guo, X. Zhao, P. Xiao, Effects of the $\beta$ phase size and shape on the oxidation behavior of NiCoCrAlY coating, Corros. Sci. 145 (2018) 262-270.

[22] F.A. Golightly, The Relationship Between Oxide Grain Morphology and Growth Mechanisms for Fe-Cr-Al and Fe-Cr-Al-Y Alloys, J. Electrochem. Soc. 126 (1979) 1035.

[23] F.A. Golightly, F.H. Stott, G.C. Wood, The influence of yttrium additions on the oxide-scale adhesion to an iron-chromium-aluminum alloy, Oxid. Met. 10 (1976) 163-187.

[24] P. Shi, W. Ren, T. Zheng, Z. Ren, X. Hou, J. Peng, P. Hu, Y. Gao, Y. Zhong, P.K. Liaw, Enhanced strength-ductility synergy in ultrafine-grained eutectic high-entropy alloys by inheriting microstructural lamellae, Nat Commun, 10 (2019) 489.

[25] C. Wagner, Theoretical Analysis of the Diffusion Processes Determining the Oxidation Rate of Alloys, J. Electrochem. Soc. 99 (1952) 369-380.

[26] H.E. Evans, M.P. Taylor, Diffusion Cells and Chemical Failure of MCrAlY Bond Coats in Thermal-Barrier Coating Systems, Oxid. Met. 55 (2001) 17-34.

[27] A.G. Evans, D.R. Mumm, J.W. Hutchinson, G.H. Meier, F.S. Pettit, Mechanisms controlling the durability of thermal barrier coatings, Prog. Mater. Sci. 46 (2001) 505-553.

[28] N.P. Padture, M. Gell, E.H. Jordan, Thermal barrier coatings for gasturbine engine applications, Science, 296 (2002) 280-284.

[29] G. Wang, B. Gleeson, D.L. Douglass, A diffusional analysis of the oxidation of binary multiphase alloys, Oxid. Met. 35 (1991) 333-348.

[30] D. Mercier, B.D. Gauntt, M. Brochu, Thermal stability and oxidation behavior of nanostructured NiCoCrAlY coatings, Surf. Coat. Technol. 205 (2011) 4162-4168. 
[31] E. Hejrani, D. Sebold, W.J. Nowak, G. Mauer, D. Naumenko, R. Vaßen, W.J. Quadakkers, Isothermal and cyclic oxidation behavior of free standing MCrAlY coatings manufactured by high-velocity atmospheric plasma spraying, Surf. Coat. Technol. 313 (2017) 191-201.

[32] J. Lu, Y. Chen, C. Zhao, H. Zhang, L. Luo, B. XU, X. Zhao, F. Guo, P. Xiao, Significantly improving the oxidation and spallation resistance of a MCrAlY alloy by controlling the distribution of yttrium, Corros. Sci. 153 (2019) 178-190.

[33] J.D. Kuenzly, D.L. Douglass, The oxidation mechanism of $\mathrm{Ni}_{3} \mathrm{Al}$ containing yttrium, Oxid. Met. 8 (1974) 139-178.

[34] J.A. Nychka, D.R. Clarke, Quantification of Aluminum Outward Diffusion During Oxidation of FeCrAl Alloys, Oxid. Met. 63 (2005) 325-352. [35] B.A. Pint, Experimental observations in support of the dynamicsegregation theory to explain the reactive-element effect, Oxid. Met. 45 (1996) 1-37. 